\title{
ADMINISTRACIÓN POR INTERVENCIÓN JUDICIAL: ALTERNATIVA PARA SUPERAR UNA CRISIS ECONÓMICA O FINANCIERA DE LA EMPRESA
}

\author{
ELIO BURGOS GÓMEZ \\ Universidad Nacional, Costa Rica \\ elioburgosgomez@yahoo.fr \\ ROXANA DURÁN SOSA \\ Universidad Nacional, Costa Rica \\ roxana.duran.sosa@una.cr
}

\section{RESUMEN}

La empresa que enfrenta una crisis económica o financiera superable puede solicitar la intervención judicial que le permitirá la moratoria de pagos de acuerdo con un plan de salvamento elaborado por un profesional en administración o finanzas, y aprobado a nivel jurisdiccional. La intervención judicial facilita la adopción de medidas gerenciales correctivas, la reorganización y administración controlada por un interventor más un comité de vigilancia, con la ventaja de que sustituye cualquier medida previa que se le oponga, obliga a los acreedores civiles y mercantiles a la instauración del procedimiento junto con la reducción de la carga financiera e impositiva. En este trabajo se expone con detalle las etapas de solicitud, trámite, gestión y conclusión de este proceso judicial que busca evitar, en lo posible, la quiebra o el concurso civil.

PALABRAS CLAVE: CRISIS, SALVAMENTO, QUIEBRA, LIQUIDACIÓN, INTERVENCIÓN JUDICIAL.

\section{ABSTRACT}

A company facing a surmountable economic or financial crisis can request a Judicial Intervention to default according to any Rescue Plan proposed by an administration or financial expert and approved by judicial authorities. Judicial interventions allow for the adoption of supervised assessment, restructuring and management by a controller and a supervision committee, with the advantage that this substitutes any other previous measure imposed; it also forces civil and commercial creditors into adopting the procedure together with a reduction on tax and financial burdens. This paper exposes in detail the method for request, filing, management and conclusion of this judicial process which, at the end, is intended to avoid the risk of bankruptcy or civil and commercial insolvency.

KEYWORDS: CRISIS, RESCUE, BANKRUPTCY, INSOLVENCY, JUDICIAL INTERVENTION.

\section{INTRODUCCIÓN}

El Instituto de la Administración y Reorganización por Intervención Judicial es un instrumento de saneamiento de las empresas, para enfrentar situaciones de crisis económicas y/o financieras que se dictaminen como superables. En términos generales, se pretende ofrecer a las empresas una forma de eludir los efectos nefastos de una posible quiebra con la cual no solo son desapoderados de sus bienes los empresarios, sino que sus efectos se extienden a:

- $\quad$ Despidos de trabajadores.

- Desatender y abandonar a los clientes.

- Se revocan contratos de alquiler de inmuebles y equipos. 
- Se eliminan las relaciones comerciales con proveedores.

- Se deja de pagar los impuestos, tasas y contribuciones a favor del Estado.

- Se incumple parcial o totalmente las obligaciones con los acreedores.

- Se generan inconvenientes para el sistema bancario puesto que en el evento de adjudicarse bienes, estos comienzan a deteriorarse por la inactividad y la obsolescencia (en el caso de muebles, equipos y maquinaria) o el abandono en el caso de los terrenos y edificaciones.

Las crisis económicas y/o financieras que enfrentan las empresas no son siempre consecuencia de los malos manejos de sus propietarios; ni todo el tiempo obedecen a la imprudencia, la impericia o la negligencia de sus administradores, ni surgen persistentemente por manipulaciones y acciones dolosas de sus personeros. Antes bien, estas crisis se originan en elementos macroeconómicos como la inflación, el desempleo, las restricciones monetarias, crediticias, la devaluación y la competencia por ganar posiciones de mercado. No son despreciables, dependiendo del giro de la empresa, las catástrofes naturales, plagas, problemas aduaneros, protestas y huelgas de trabajadores, dificultades para el transporte y hasta lentitudes generadas por el aparato burocrático del Estado.

\section{OBJETIVOS Y METODOLOGÍA}

Con este artículo se pretende que la gerencia de la empresa que enfrenta una crisis económica o financiera superable, o el/la profesional en Administración actuando como consultor(a):
- Cuente con un esquema práctico del proceso de administración y reorganización por intervención judicial.

- Incorpore los cambios en los procedimientos que se originan en las recientes modificaciones de la legislación civil, mercantil y procesal.

- Pondere el papel clave que tiene el profesional en administración de las finanzas para la elaboración y seguimiento del plan de salvamento.

- Establezca los niveles de coordinación que deberán darse, por mandato de ley, entre abogado y administrador en tanto que asesores del interventor.

- Ubique en forma gráfica los nodos críticos en donde se acrecienta el riesgo de quiebra o insolvencia, para evitar ese desenlace.

El flujo de las actividades administrativas en este proceso judicial sigue completamente lo prescrito en el texto del Código Procesal Civil vigente para la República de Costa Rica.

\section{DESARROLLO}

La reforma de 1996 al Código de Procedimientos Civiles $(C P C)$, reduce la carga que en el salvamento deban soportar las empresas financieras, particularmente las del Sistema Bancario, asimismo, conforme con el Artículo 709 CPC los beneficios de este procedimiento solamente pueden aplicarse a empresas con gran cantidad de empleados, muchos proveedores y acreedores, además de que atiendan a gran cantidad de clientes; es decir, este instituto solamente se aplicará, bajo el criterio del juez, a empresas grandes cuya quiebra provoque efectos sociales de gran magnitud. 
Con esas limitaciones, el instituto de la Administración y Reorganización por Intervención Judicial considera necesarios algunos sacrificios para los acreedores, para los administradores que serán cesados, para algunos trabajadores por la reorganización y disminución eventual de la planilla, también para algunos proveedores de materias primas, arrendantes de inmuebles, etc. La suma de todos estos sacrificios se reputan como un mal menor frente a la desaparición completa de la empresa.

En este artículo, se presenta el trámite, la discusión y los efectos del plan de salvamento, anteproyecto que forma parte del elenco de documentos que configuran la solicitud de Intervención Judicial. La descripción de su trámite se hace lo más apegada posible a la ley, junto con aspectos doctrinarios de académicos y juristas especializados en procesos concursales, además de elementos jurisprudenciales y ejemplos de casos tramitados en nuestros tribunales de justicia.

\section{El plan de salvamento}

Para entablar el proceso de Administración y Reorganización por Intervención Judicial, se establece la necesidad de presentar un Plan de Salvamento conforme con el Artículo 713 del Código Procesal Civil, que en su inciso 3) habla de la necesidad de:

3.- Un plan, elaborado por un profesional en administración o en finanzas, de reconocida capacidad técnica e idoneidad moral e inscrito en el colegio respectivo. Este plan contendrá las razones que amparan la viabilidad económica y financiera de la empresa así como las medidas de reorganización que deberán adoptarse para superar la crisis y un cronograma de ejecución de ese plan, con señalamiento del plazo para cumplirlo. Cuando la empresa tenga autorización de oferta pública de títulos valores, la Comisión Nacional de Valores podrá colaborar realizando los análisis necesarios y elaborando el mencionado plan (p.281).

El Código de Procedimientos Civiles prescribe que la solicitud del deudor y el plan de salvamento se acompañará de:

- Las declaraciones tributarias y sus anexos.

- El estado del activo y del pasivo de la empresa.

- Cualquier documento que apoye la exposición sobre la crisis económica o financiera por la que atraviesa la empresa.

El incumplimiento de alguno de estos documentos mandatorios, y muy especialmente del Plan de Salvamento, ocasionará que el juzgado en el plazo improrrogable de cinco (5) días se enmiende, con la prevención de que si no se hace, la solicitud será rechazada de plano (p. 281).

Conforme con el Artículo 714 del Código Procesal Civil, este plan debe contener:

- La forma de administración controlada por un interventor y un comité de vigilancia.

- Medidas de reorganización de la empresa.

- Sustitución de los administradores.

- Moratoria de pagos (total, parcial o escalonada).

- Medidas gerenciales correctivas.

- Otras medidas de saneamiento. 
En términos generales, el plan de salvamento debe presentar:

- Las razones que expliquen la viabilidad de la empresa.

- Las medidas de reorganización.

- El cronograma de acciones.

Cuando el juzgado se pronuncie sobre la admisibilidad del procedimiento, al tenor del Artículo 719 del CPC, basado en la complejidad o tamaño de la empresa y en la estimación del Juez, se podrá nombrar hasta "dos asesores del interventor, entre quienes podrá designar un abogado y un administrador de empresas con énfasis en finanzas; ambos deberán estar colegiados y comparecerán al despacho judicial, en un plazo de tres (3) días, para aceptar y jurar el cargo" (p. 284).

Seguidamente, conforme al inciso 8) del Artículo 719 CPC, se debe hacer:

La convocatoria a todos los acreedores para que se apersonen a reclamar sus derechos y presentar las observaciones que estimen pertinentes al plan, dentro de los quince (15) días hábiles siguientes al de la publicación de la resolución, que deberá hacerse por una vez, en un periódico de circulación nacional (p.286).

Una vez que se ha nombrado al interventor, entre sus atribuciones y deberes, el Artículo 721 $C P C$, respecto del plan de salvamento le obliga a:

4.- Examinar el plan de administración propuesto por la empresa y, siempre con el auxilio del comité asesor, informar al juzgado, mediante la relación circunstanciada de la situación de la empresa, acerca de su procedencia o bien, sugerir las modificaciones necesarias, para que el plan sea eficiente en relación con el salvamento de la empresa (p.288)

En el caso que este proceso de gestión administrativa por intervención judicial hubiera sido solicitado por un acreedor, el juzgado girará una orden al apoderado de la compañía o a su representante de completar los requisitos establecidos en artículo 713 CPC sin faltar el plan de salvamento, lo cual deberá cumplirse en el plazo perentorio de quince (15) días. Una vez que el juez tenga por completados formalmente estos documentos indispensables, se producirán los efectos señalados en el artículo 715 CPC referente a la obligación de girar comunicación a todos los acreedores sobre la solicitud de proceso de administración judicial y especificar el juzgado ante el cual se ventila el proceso de intervención.

La resolución del juzgado la cual admite la solicitud de administración y reorganización por intervención judicial, producirá:

- $\quad$ Efectos formales (Art. 723 CPC).

- $\quad$ Efectos sustantivos (Art. 724 CPC).

ARTÍCULO 723 CPC.- Efectos formales de la resolución inicial

La resolución que declare válidamente presentada y admitida la solicitud del promovente, provocará la paralización de las pretensiones ejecutivas individuales, comunes, hipotecarias, prendarias y de cualquier otro tipo.

Se exceptúan:

1. Aquellas en que hubiere remate ya debidamente notificado al solicitante.

2. Aquellas en que los bienes que se pretende vender o rematar no pertenezcan a la intervenida. 
3. Las alimentarias.

4. Las laborales.

5. Aquellas en las que el bien le pertenezca al deudor, pero no sea indispensable para el funcionamiento normal de la empresa.

Dictada la resolución inicial, no podrá promoverse ningún otro procedimiento concursal, mientras no exista resolución firme que la rechace de plano. Las peticiones de quiebra o de concurso civil se suspenderán de pleno derecho si, en el momento de presentarlas, no se hubiere pronunciado la declaratoria respectiva (p.289).

Mientras los acreedores no tengan la posibilidad de ejercitar su derecho, no correrá, en su perjuicio, plazo alguno de prescripción ni de caducidad (p.289).

Los efectos sustantivos de la Resolución Inicial Judicial son:

La suspensión de pagos establecida en el proyecto del plan presentado para su discusión, será aplicable a las obligaciones vencidas del deudor, salvo las que no resulten afectadas por el procedimiento de intervención (...) Los acreedores afectados por la suspensión podrán recibir únicamente los pagos parciales, conforme al procedimiento de ejecución del plan de salvamento (p.290).

La inexigibilidad de las multas administrativas o fiscales, de cualquier naturaleza y de las cláusulas penales de carácter contractual. Los acreedores de las obligaciones a que estas cláusulas se refieren, sólo podrán percibir intereses en los términos resultantes del plan, salvo que el monto fuere in- ferior; en cuyo caso será ese el monto por cubrir (p.290).

La obligación del solicitante de iniciar la aplicación del plan de administración por él propuesto. Para computar el plazo del proceso de administración mencionado en el artículo 732 CPC, se tomará, como fecha inicial, aquella en la que el juzgado dicte el auto que dé por presentada válidamente la solicitud (p.291).

En tanto dure el proceso, se analiza y aprueba el plan de salvamento de la compañía, se ocuparán de la administración los órganos previstos en los estatutos de las personas jurídicas correspondientes, el apoderado de la empresa o el interventor en el supuesto establecido en el inciso 6) del párrafo 3 del artículo 719 CPC, con la asesoría y la fiscalización señaladas en el inciso 4) de ese mismo artículo. Únicamente estarán facultados para ejecutar las gestiones regulares de la administración de la compañía, indispensables a fin de garantizar su normal funcionamiento.

La totalidad de los acreedores, incluidos los que no figuran en la nómina proporcionada por el deudor, tendrán que exigir el derecho a que se les considere como acreedores y estarán facultados para presentar en forma escrita correcciones al plan, dentro del plazo de quince (15) días.

Para los deudores que no figuran en las nóminas facilitadas de previo, se otorgará audiencia por tres (3) días al interventor y al deudor o a su representante $y$, una vez conocidos los documentos probatorios aportados se emitirá la resolución correspondiente. El trámite de la comprobación, en lo referente a estos acreedores y a los no aceptados por el interventor, se hará en forma incidental y no detendrá el transcurso del trámite de análisis y aprobación del plan de salvamento. 
El Artículo 729 CPC acerca del proceso para analizar y discutir del plan prescribe que:

Dentro del mes siguiente a la admisión del procedimiento, el interventor y los demás miembros del comité, nombrado el primero, en forma conjunta o separada, presentarán un informe pormenorizado acerca del plan y emitirán su opinión (p.293).

Transcurrido el emplazamiento y rendido el dictamen, si el juzgado lo considerare necesario, convocará al titular de la empresa o a sus representantes legales, al promovente si no fuere el deudor, al interventor, a los acreedores que presentaron objeciones al plan y a los miembros del comité asesor, a una comparecencia dentro de ocho (8) días, para discutir los pormenores del plan y las observaciones, de lo cual se levantará un acta concisa (p.294).

A fin de emitir el pronunciamiento, podrán ordenarse las pruebas necesarias para mejor proveer, las cuales deberán sustanciarse en forma breve (p.294).

En necesario aclarar que esta convocatoria es facultativa del juzgado y no forma parte de los procedimientos obligatorios.

Discutido el plan, dentro de los ocho (8) días siguientes a:

- La presentación del informe pormenorizado y opinión del interventor y del comité asesor.

- La conclusión del emplazamiento.

- La celebración de la comparecencia facultativa (si fue ordenada).

- La sustanciación de las eventuales pruebas ordenadas.
El juzgado deberá pronunciarse acerca del plan propuesto:

ARTíCULO 730 CPC. (...) De aprobarlo, en la parte dispositiva de la resolución, deberá incluir el contenido autorizado, con las modificaciones pertinentes (p.294).

Las consecuencias jurídicas de la aprobación del plan de salvamento se listan en el Artículo 731 CPC. Una vez aprobado en firme el plan:

1. Sustituirá cualquier medida adoptada anteriormente que se le oponga

2. Obligará a los acreedores (excepto los alimentarios y laborales) a la instauración del procedimiento.

3. Hará fenecer los procesos suspendidos (con las excepciones del Artículo 723 CPC) sin responsabilidad procesal para la empresa.

Acerca de la duración de este plan, el cuerpo normativo procesal civil establece en su Artículo 732 :

\section{ARTíCULO 732 CPC.- Duración del plan}

Salvo acuerdo escrito de las tres cuartas partes de los acreedores, el plan no podrá durar más de tres años a partir de la firmeza de la resolución inicial (p.295).

Elemento debatido por académicos y doctrinarios de los procesos concursales sobre que, dependiendo del tipo y complejidad de la empresa, este plazo podría ser mayor o menor y definirse jurisprudencialmente y no por ley.

En el tiempo de aplicación del plan de salvamento, la empresa requerirá ser:

- Administrada.

- Fiscalizada.

- Dirigida y supervisada. 
La administración de la empresa puede ser realizada por los personeros o, si se considera necesario, por el interventor.

La fiscalización recae sobre el interventor y los demás miembros del comité asesor (2 asesores, 2 representantes de los acreedores, 1 representante de los trabajadores). En el caso de que el interventor pase a administrar, la fiscalización descansará sobre el comité asesor. Por lo menos una vez cada tres meses, el interventor y los otros componentes del comité asesor, corroborarán si el plan se está cumpliendo en los términos pactados y emitirán un comunicado sobre su criterio.

La dirección y supervisión judicial es potestad el juzgado. En el evento de que se soliciten modificaciones al plan inicial, a petición de partes, el juez las aprobará conforme a lo dispuesto en el Artículo 734 del Código Procesal Civil:

\section{ARTíCULO 734.- Modificación del plan}

Después de oír el parecer de los interesados, el juzgado podrá autorizar modificaciones del plan, siempre y cuando resulten indispensables para el saneamiento y la preservación efectiva de la empresa y no sobrepasen las limitaciones legales dispuestas para las medidas de salvamento (p. 296).

\section{Finalización del proceso}

El Proceso de Administración y Reorganización por Intervención Judicial puede llegar a su conclusión en forma normal o anormal.

Las formas de terminación normal están reguladas en los Artículos 738 y 739 del Código de Procedimientos Civiles, y se llega a ellas por:

- Terminación del plazo de la intervención judicial.

- Saneamiento anticipado de la empresa.
Transcurrido el Plazo del Plan, el proceso de intervención judicial concluye de pleno derecho y cesan los efectos que se crearon con la aprobación del Plan de Salvamento. Se espera que al finalizar el plazo, el deudor pueda demostrar con sus estados de resultados y balances de situación, que se está en capacidad de enfrentar los pasivos en la forma en que estaban pactados previamente.

La empresa vuelve a su normalidad administrativa, aunque tenga que atender deudas, pues estas forman parte del giro normal de los negocios. Las deudas que no puede arrastrar son los honorarios del interventor y los costos del proceso, puesto que su incumplimiento constituye falta grave y ocasiona que se decrete la quiebra o el concurso civil según lo prescribe el Código Procesal Civil en el artículo 739 in fine (p. 298).

La conclusión anticipada de la intervención judicial, debe tramitarse ante el juzgado cuando se ha logrado el saneamiento económico y financiero de la empresa. En el Artículo 739 del CPC se establece que "De la solicitud y de los documentos acompañados, se dará audiencia al interventor y a los acreedores apersonados, por tres (3) días, para que manifiesten lo que a bien tengan" (p. 297). Si la solicitud fuera presentada conjuntamente por el intervenido y sus acreedores, no será necesaria esta convocatoria.

Terminada la audiencia, el juzgado se pronuncia sobre la solicitud de conclusión del procedimiento y en caso de aprobarla, dará por finalizada la intervención judicial, ordenará el archivo del expediente y fijará los honorarios pendientes de pago para que la empresa deposite en el plazo señalado. El incumplimiento de este pago constituye falta grave y ocasiona que se decrete la quiebra o la insolvencia. 
El fenecimiento anormal de la intervención judicial sucede cuando:

- Se comprueba que la crisis económica y financiera que enfrenta la empresa es insalvable

- Por incumplimiento, obstaculización, ocultamientos o falseamientos del deudor

En dichas situaciones la conclusión del procedimiento de intervención judicial se tramita a solicitud del interventor o de cualquier interesado, y si el juez estima procedente la petición, emitirá una resolución decretando la quiebra o el concurso civil.

Los eventuales incumplimientos del deudor se enumeran en los incisos del 2) al 6) del Artículo 740 del Código Procesal Civil, y resumidamente son:

- Incumplir las prestaciones prometidas en el plan

- Incumplimientos graves que afecten la ejecución del plan

- Incumplir depósitos a favor del juzgado para gastos del procedimiento

- Impedir u obstaculizar la fiscalización o a los encargados de realizarla

- Si ha ocultado activos, aumentado pasivos o falseado datos

Al tener conocimiento de esto último, sea de oficio o a solicitud de parte, el juzgado dará audiencia por tres (3) días al interventor y al deudor para que aporten documentos probatorios o en contrario. "La gestión será puesta en conocimiento del deudor, el interventor y los representantes de los acreedores y trabajadores, por un plazo de tres (3) días. Una vez sustanciada, se resolverá lo que corresponda y, si se estimare procedente la petición, en el mismo pronunciamiento se decretará la quiebra o el concurso civil" (p. 298-299).

\section{RESULTADOS Y DISCUSIÓN}

El tema que nos ha convocado a investigar es un instituto de protección de una empresa en crisis económica y financiera, pero que puede ser superada si se cumple con una serie de requisitos y se enfrentan sacrificios de socios, trabajadores, proveedores, financistas acreedores y hasta de los clientes.

A lo largo de este ensayo, se han revisado los aspectos procedimentales que deben seguirse para el salvamento de la empresa sometida a la Intervención Judicial. Desde la solicitud, que puede ser planteada por el deudor o por algún acreedor. Se mencionaron las condiciones de admisibilidad, se analizó el elenco de documentos que deben acompañar la solicitud de intervención, centrándonos en el plan de salvamento, luego de su elaboración por un profesional en Administración o en Finanzas, el cronograma de su aprobación y puesta en ejecución, así como la forma de conclusión tanto normal como anormal.

Se ha evidenciado que cuando una empresa enfrenta una crisis económica y/o financiera, pende sobre su cabeza la espada de la quiebra o el concurso civil, según corresponda. Los momentos críticos de la quiebra se ubican desde antes de la solicitud, si existiere cesación de pagos, puesto que cualquier acreedor afectado puede pedir la liquidación.

También existe amenaza de quiebra cuando los documentos que acompañan a la solicitud no están bien fundamentados, aunque el Juez puede hacer una prevención para que se subsane so pena de declararlo inadmisible. La 
Resolución sobre la admisibilidad del proceso de intervención vuelve a poner al Juez ante la disyuntiva de admitir o declarar el concurso. Tras el debate del Plan de Salvamento se vuelve plantear la posibilidad de quiebra y si el plan es insubsistente, el Juez puede declararla.

Durante la implementación del Plan y la Intervención Judicial, la empresa no está exenta de esta amenaza puesto que la crisis puede ser declarada insuperable, o podría presentarse incumplimientos diversos por parte del deudor. En todo este proceso se camina sobre una superficie angosta hasta llegar a la conclusión del proceso que puede terminar en forma normal o con la declaratoria de quiebra.

En la fase conclusiva del proceso de Intervención Judicial, incluso al cumplirse el plazo o solicitar su levantamiento anticipado, la empresa pasa por momentos críticos pues bastaría con incumplir con el pago de honorarios del interventor o dejar de pagar sumas al juzgado, para que el Juez decrete la quiebra o el concurso civil. Por supuesto que la forma anormal de terminar el proceso es catastrófica para los accionistas liquidados, los trabajadores despedidos, los contratistas revocados y las empresas financieras que recuperarán solo parcialmente sus acreencias.

\section{CONCLUSIONES}

Si bien puede argumentarse que la salud económica y financiera de las empresas obedece al interés primordial de sus propietarios, no es menos cierto que de las empresas obtienen salarios los trabajadores, honorarios los profesionales, comisiones los distribuidores, arriendos los dueños de inmuebles, intereses los bancos, utilidades los accionistas e impuestos, tasas y contribuciones especiales la Hacienda Pública. La bonanza de las empresas es también fuente de satisfacción para los consumidores que adquieren bienes y servicios a precios competitivos y en lugares accesibles, que de otra manera o se privarían de ellos o tendrían que importar con el consiguiente gasto de divisas para el país.

La Administración por Intervención Judicial es una herramienta que posibilita la sobrevivencia de empresas que atraviesan crisis económicas y financieras superables. Es importante destacar el papel del profesional en administración y finanzas en el diagnóstico de las causas de la crisis, la elaboración del plan de salvamento y la gestión del proceso. Se ha visto que lleva un trámite delicado, sin embargo, sigue siendo la última tabla de salvación e instrumento jurídico que posibilita la continuidad de la empresa en crisis.

\section{REFERENCIAS}

Asamblea Legislativa de la República de Costa Rica. Ley n. ${ }^{\circ}$ 7130 Código Procesal Civil. (2013). Con anotaciones sobre acciones de inconstitucionalidad por Gerardo Parajeles Vindas. San José: Investigaciones Jurídicas S.A.
Recibido: 17 de agosto de 2014 Aceptado: 18 de setiembre de 2014 


\section{FLUJOGRAMA DE DEL PROCESO DE ADMINISTRACIÓN POR INTERVENCIÓN JUDICIAL}

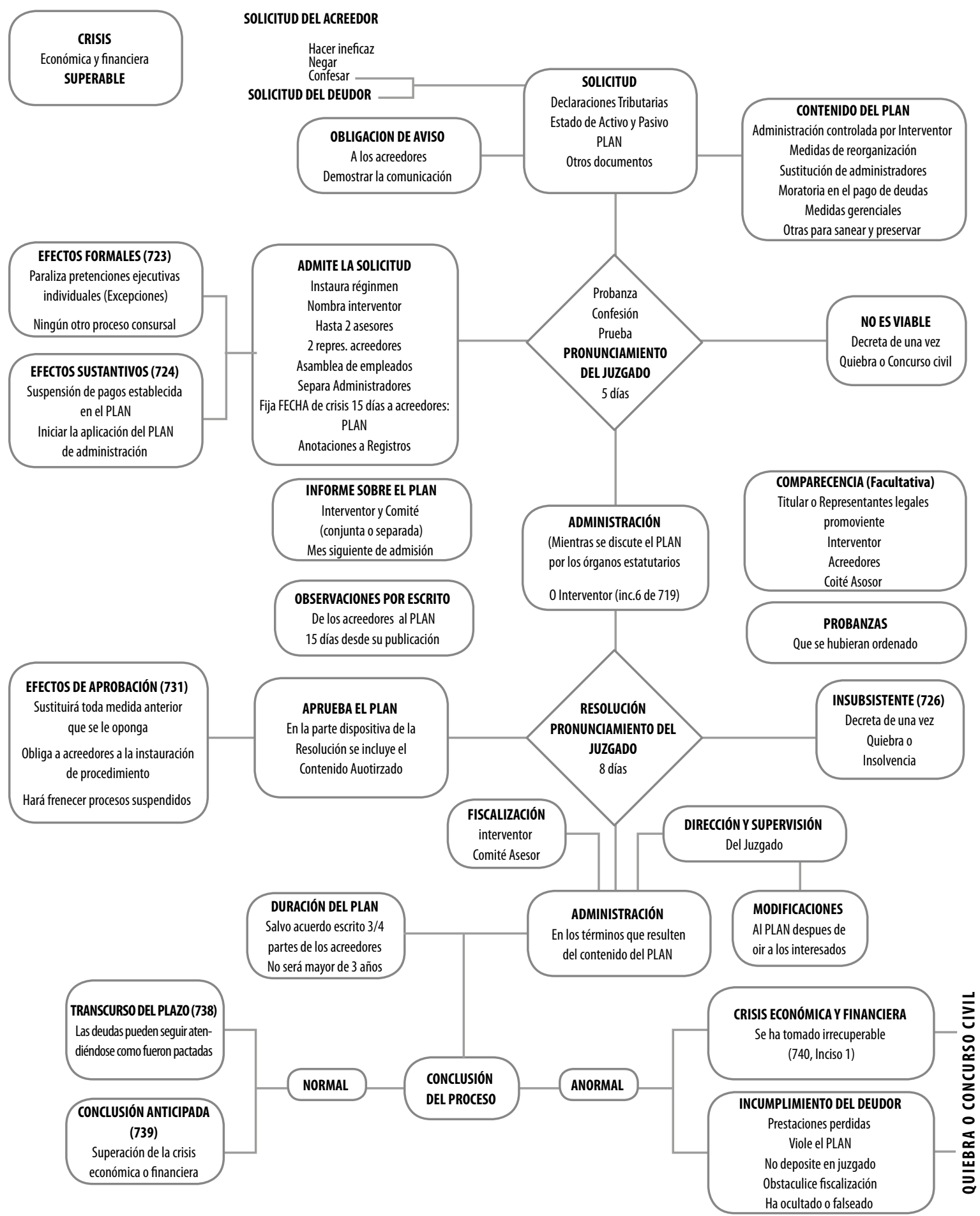

Fuente: Elaboración de los autores con base en el Código Procesal Civil de Costa Rica. 